Historic, Archive Document

Do not assume content reflects current scientific knowledge, policies, or practices. 



\section{PLANTING ENGELMANN SPRUCE: A99.9}

a field guide by Frank Ron to

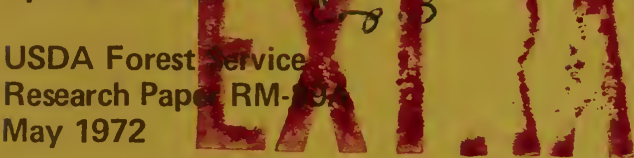

Rocky Mountain Forest and

Range Experiment Station

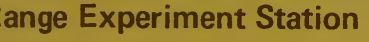




\section{FOREWORD}

This field guide was prepared to provide the planter with the techniques needed to estab-

lish Engelmann spruce seedlings successfully. Planting principles are discussed in detail in USDA Forest Service Research Paper RM-89, "Planting Engelmann Spruce," which emphasizes the relationship between the physiological and silvicultural requirements of spruces and the environmental conditions to which seedlings are exposed.

Rocky Mountain Forest and Range Experiment Station Forest Service 240 West Prospect

U. S. Department of Agriculture Fort Collins, Colorado 80521 


\title{
PLANTING ENGELMANN SPRUCE
}

\author{
A Field Guide
}

\author{
by \\ Frank Ronco
}

Engelmann spruce can be successfully planted in the Central and Southern Rocky Mountains! The job will not be easy, and in most instances it will cost more than planting other species, but it can be done. We have much of the basic knowledge and experience to carry out each phase of the planting operation successfully--stock production, storage, transportation, planting, and plantation protection. No plantation is likely to succeed, however, unless all phases are satisfactorily performed.

The need to control each operation adequately is more critical for spruce because of the harsh environment typical of most spruce-fir sites. After seedlings leave the nursery, they may be dehydrated, exposed to intense light, heated excessively, frozen in midsummer, attacked by disease, browsed, or trampled. This field guide was prepared to show the planter how to avoid or reduce the impact of those adverse factors. The relationship between the physiological and silvicultural requirements of spruce seedlings and their environment are discussed in detail in the companion Research Paper upon which this field guide is based.

\section{SPRUCE SEEDLINGS NEED PROTECTION}

Spruce seedlings planted in the open generally do not survive very long. They are damaged by high light intensities--a process known as solarization--and die when exposed to full sunlight for prolonged periods. Open-grown seedlings are also exposed to temperature extremes. High temperatures increase water loss from both the plant and soil by transpiration and evaporation. Freezing temperatures, which occur during most growing seasons, kill nearly all current growth. 

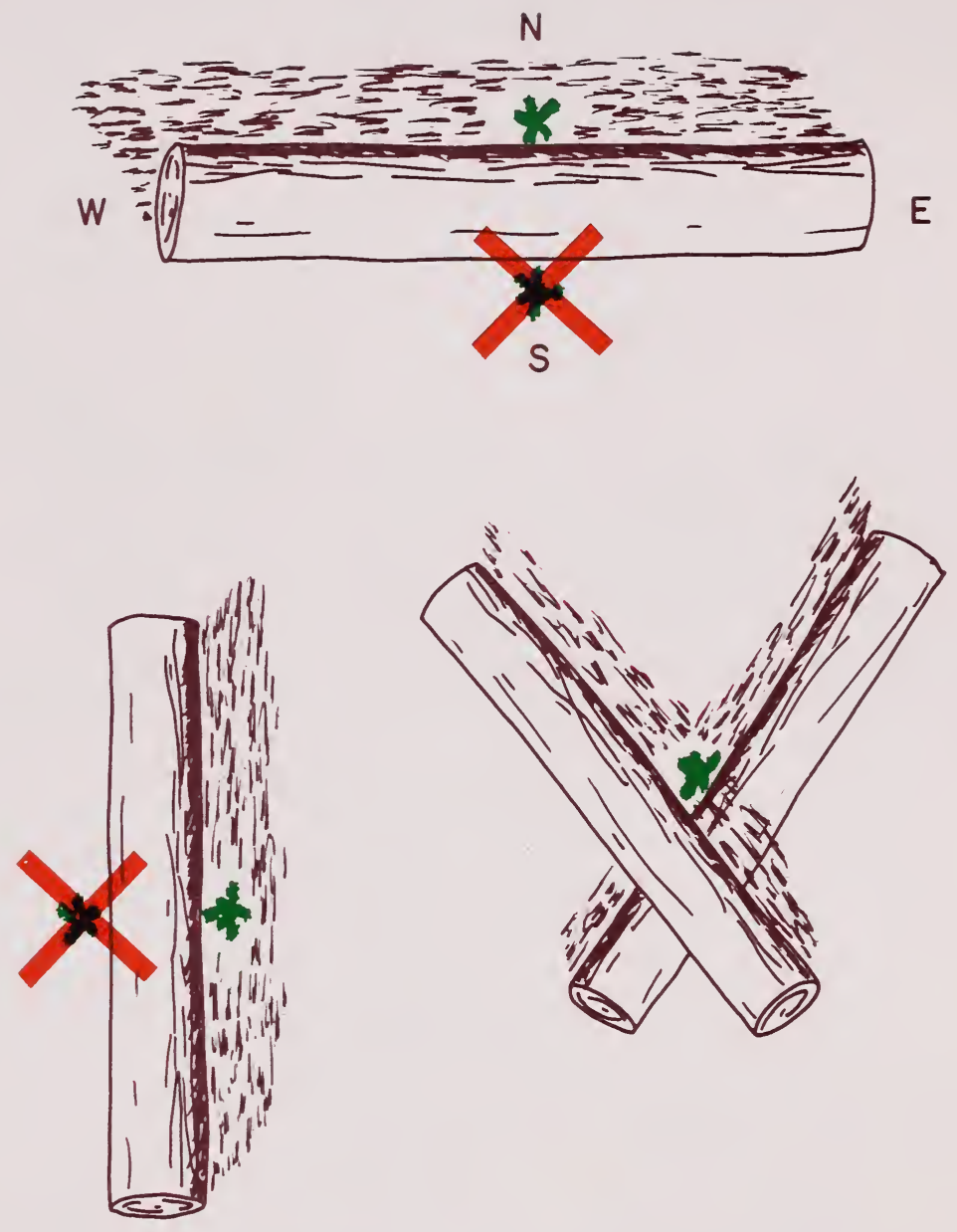

Logs, stumps, and slash provide suitable microsites for planted seedlings if (1) planting spots are properly located alongside such cover, and (2) seedlings are placed close enough (within 3 inches) to cover so that they are shaded. Often, two logs can be crossed to create a new microsite or improve an existing one by forming a " $V$ " structure which offers maximum protection by shading a seedling on three sides. Loose bark on stumps and logs, which can slip off and smother seedlings, should be knocked off with the planting tool. 
If dead material is not available, open cover of willows, potentilla, fireweed, or species of similar growth forms may be used for protaction. Dense, tall vegetation, however, as well as small mounds or hummocks and depressions, are not good planting spots.

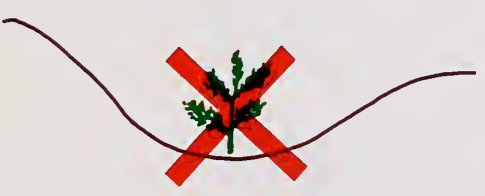

Silt smothers seedling

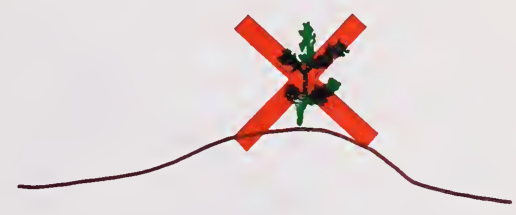

Soil dries out rapidly

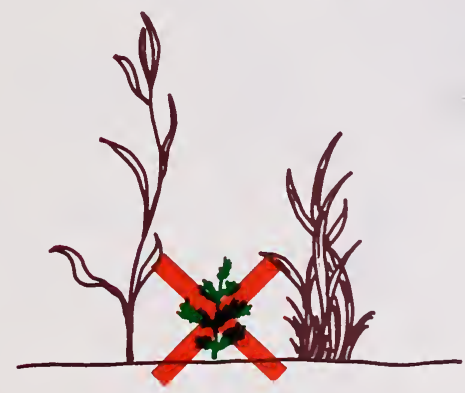

\section{Cured vegetation smothers seedling}

\section{PLANTING SEASON}

Spring is the best time to plant Engelmann spruce. The planting season is normally between May 25 and June 25, but it may be extended in some years because of late snowmelt. Planting after July 10, however, increases the risk of exposing seedlings to freezing fall temperatures before they become cold resistant. 


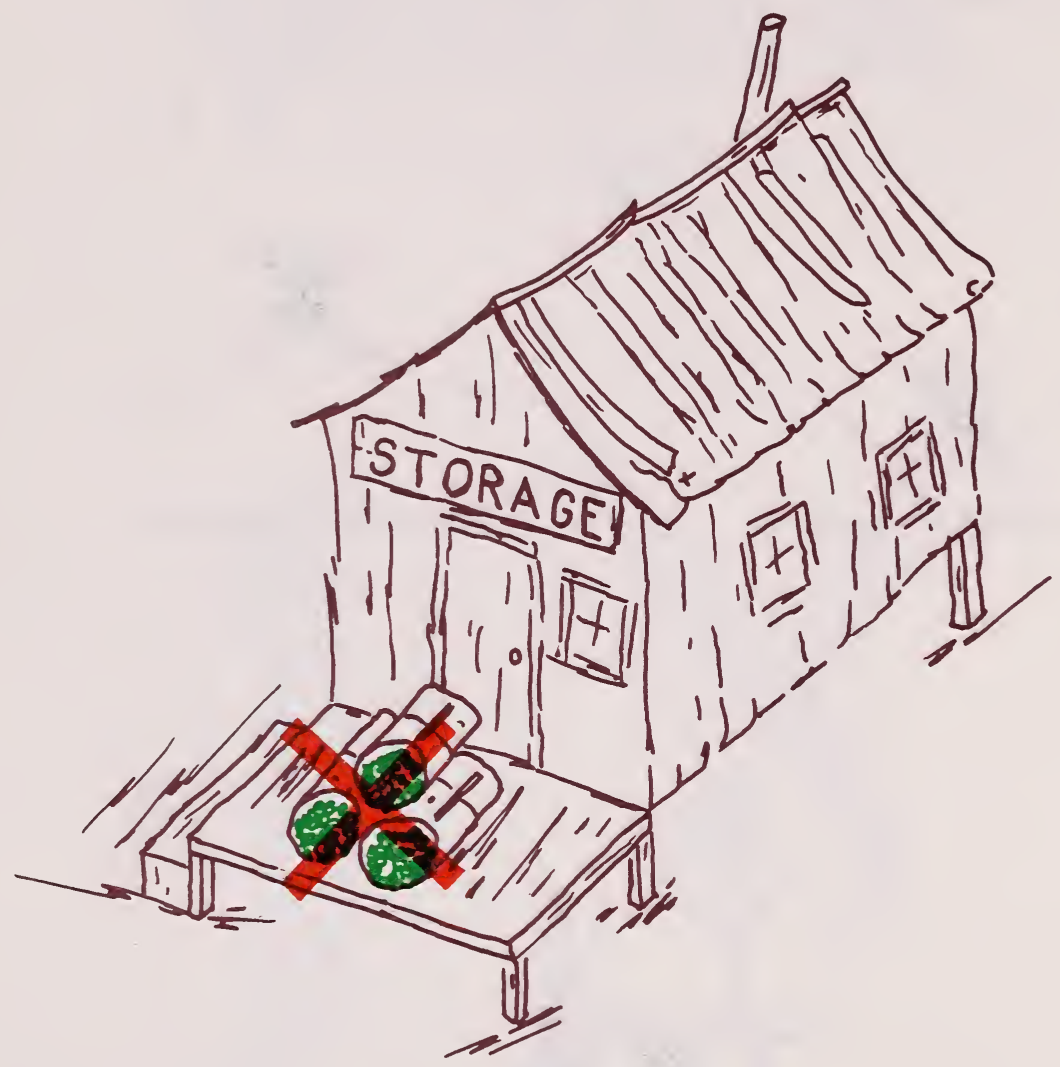

REMEMBER! Seedlings are dormant, but living, when they are loaded at the nursery--keep them in this condition. Transport and store seedlings in facilities that are draft free, cool, and moist, but keep no more trees in temporary storage than can be planted in 1 week or less. Use refrigerators, insulated container units, cellars, or for a few days, even snowbanks. Work in areas sheltered from wind and direct sunlight when transferring seedlings to planting bags or trays. Continue care of trees during planting in a manner that duplicates, within practical limitations, good storage practices. 
Since newly planted seedlings depend on existing root systems for water uptake until new growth extends into untapped moisture reserves, close contact between soil and roots is absolutely necessary. This can be accomplished best by using a mattock as a planting tool:

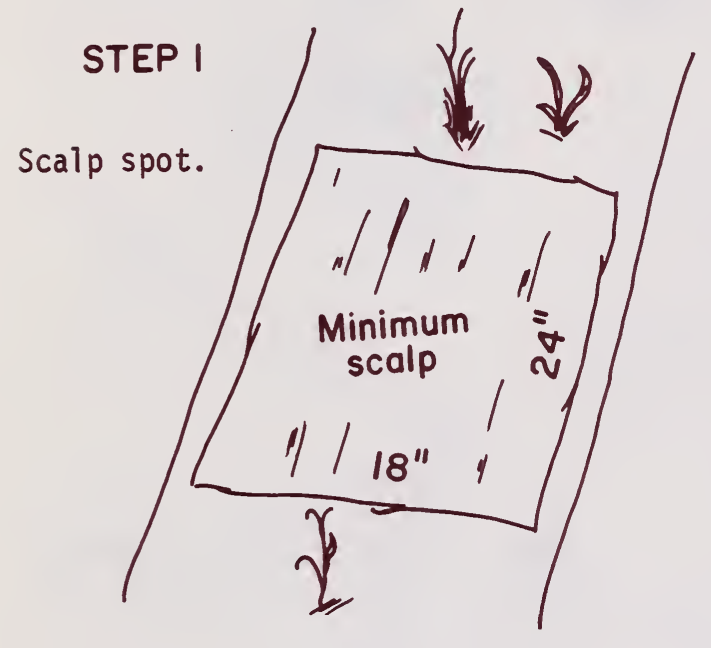

STEP 2

Scrape litter, dry soil, or other debris from spot.

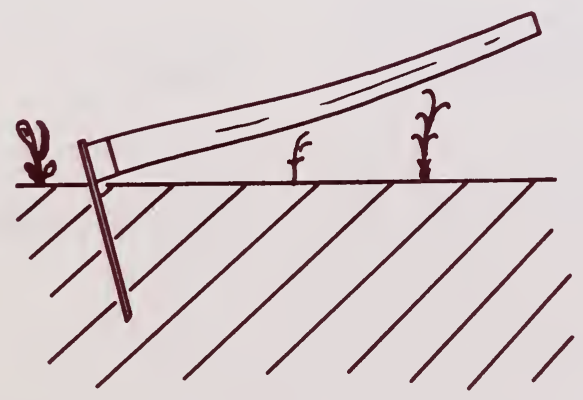

\section{STEP 3 \\ Sink mattock to depth of blade.}




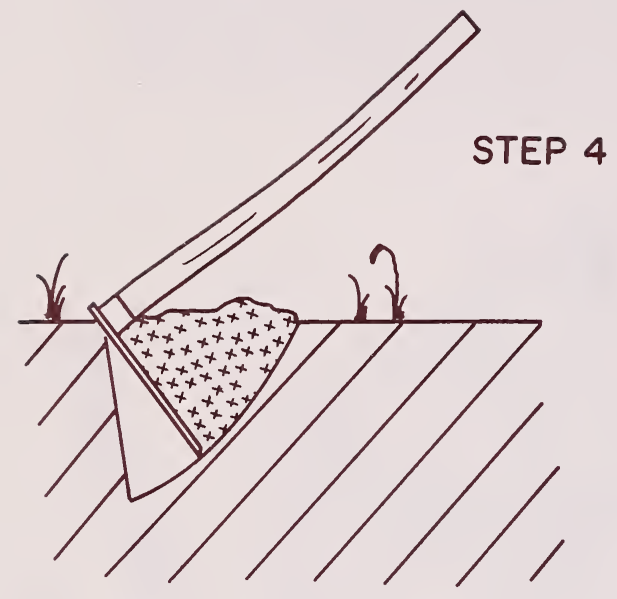

Lift handle sharply.

\section{STEP 5}

Pile loosened soil near hole. STOP!

Skip hole if it is not

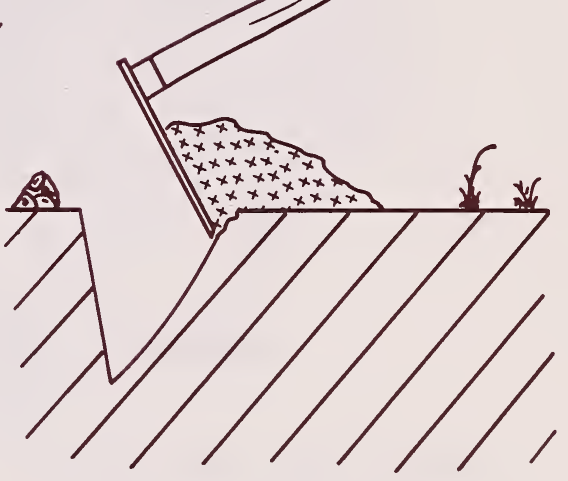
in mineral soil.

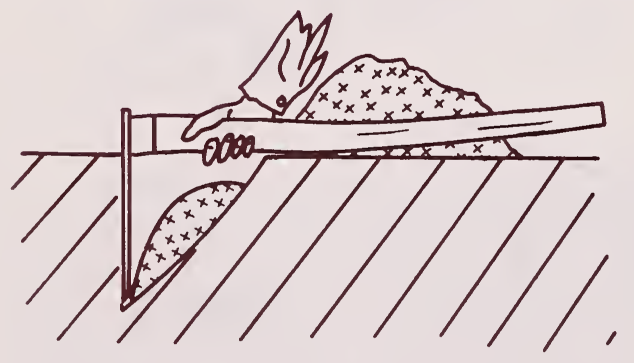

\section{STEP 6}

Trim rear wall of hole to vertical. 

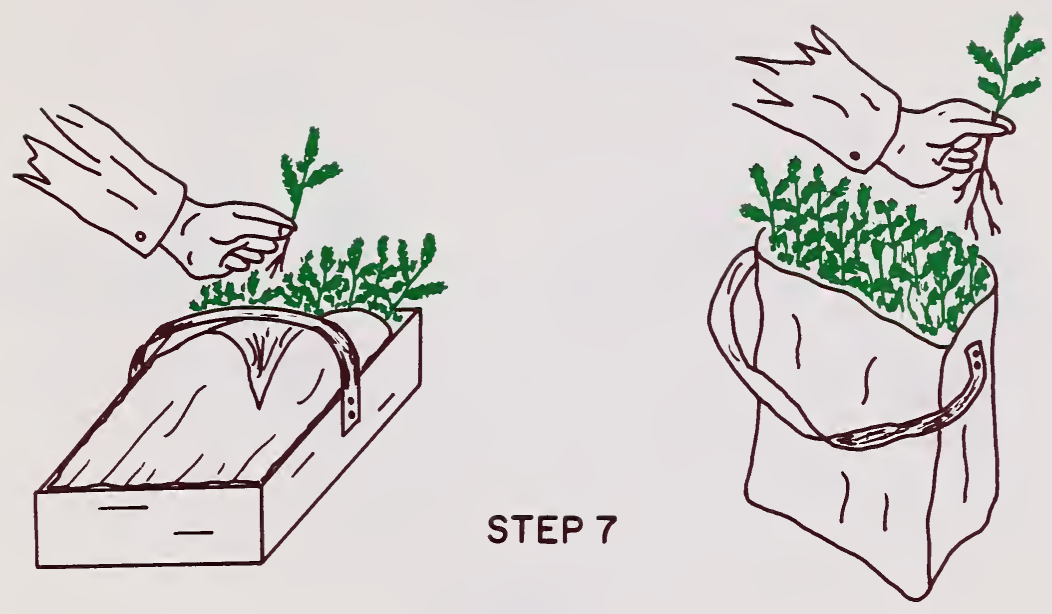

Grasp stem near root collar--

DO NOT tear foliage or roots--

KEEP container in shade and roots covered with wet moss-

DO NOT expose seedling before hole is dug.

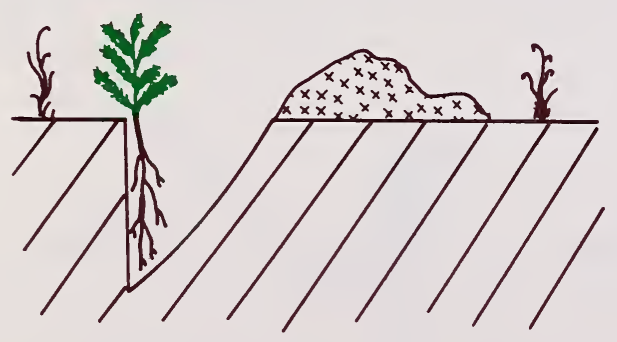

\section{STEP 8}

Spread roots against rear wall with root collar at or just below ground level-DO NOT FORCE ROOTS INTO L-, JOR U-SHAPED POSITIONS. 


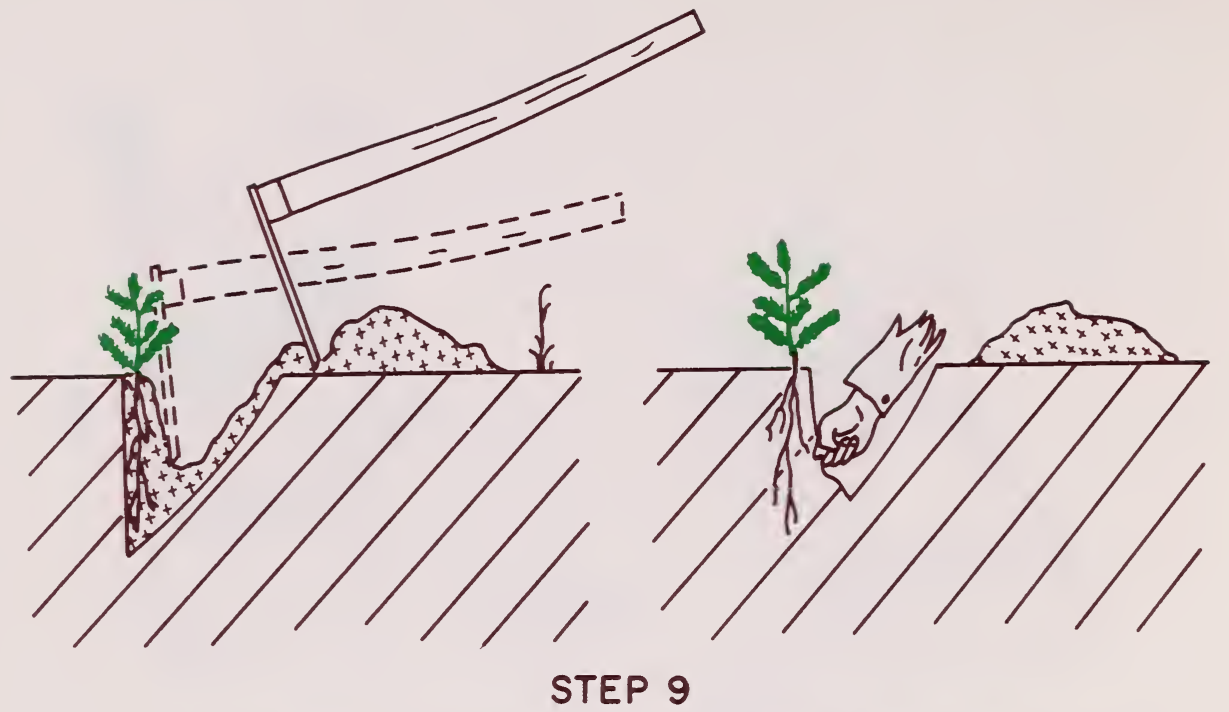

Pack about 1 inch of MOIST soil around roots with toe of mattock or by hand--

BE SURE SOIL IS FREE OF ROCKS AND LITTER.

ERFORM STEPS 9 AND 10 CAREFULLY TO PREVENT INJURY TO FOLIAGE AND ROOTS.
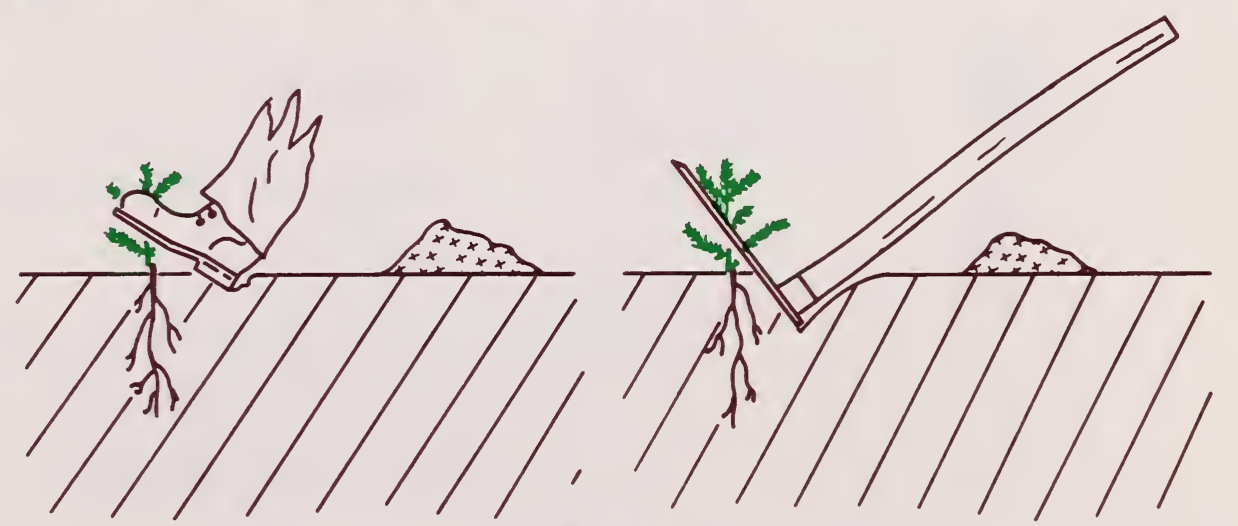

STEP 10

Fill hole with MOIST soil and pack TIGHTLY with heel of mattock or boot. 


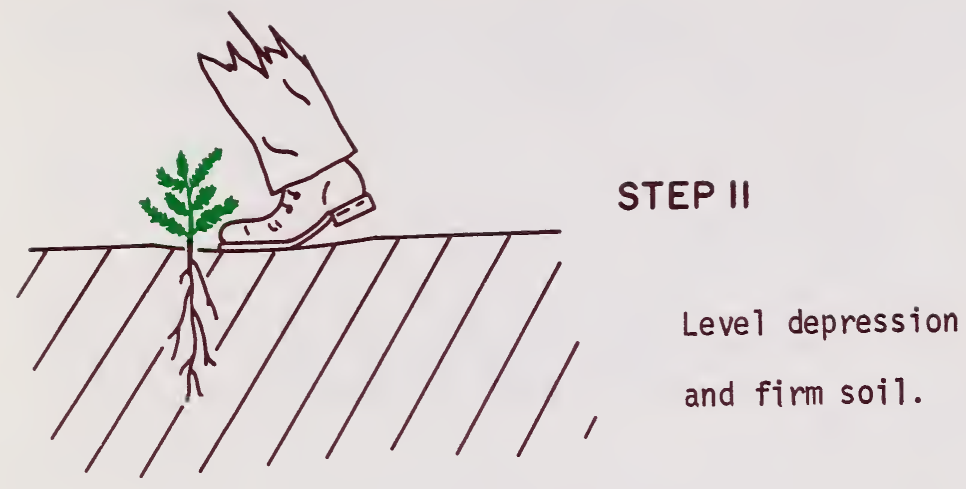

STEP 12

Mulch spot with

LOOSE SOil or litter.

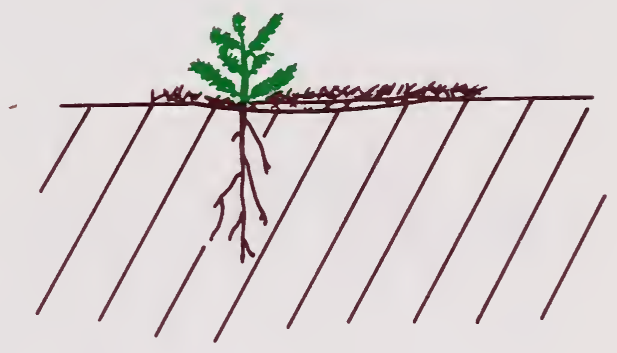


The reforestation project is not completed when the last seedling is planted! An adequate number of seedlings for a representative sample of planter and topographic variation should be staked. Survival data and causes of injury or mortality should be recorded at the end of the lst, and the beginning of the 2 nd and $3 \mathrm{rd}$ growing seasons to measure success and identify potential risks to plantations.

Plantations must be protected against trampling by livestock until trees are at least 3 feet tall to avoid serious damage. Grazing may then be permitted, but plantations should be watched closely. If browsing damage occurs, terminate grazing until terminal buds are beyond reach of animals. Rodent populations, particularly pocket gophers, must be regularly censused, and control action taken when animal numbers begin to increase during the buildup phase of the population cycle.

\section{MEASURING SUCCESS !}

The number of surviving seedlings is the only true indicator for judging regeneration success!
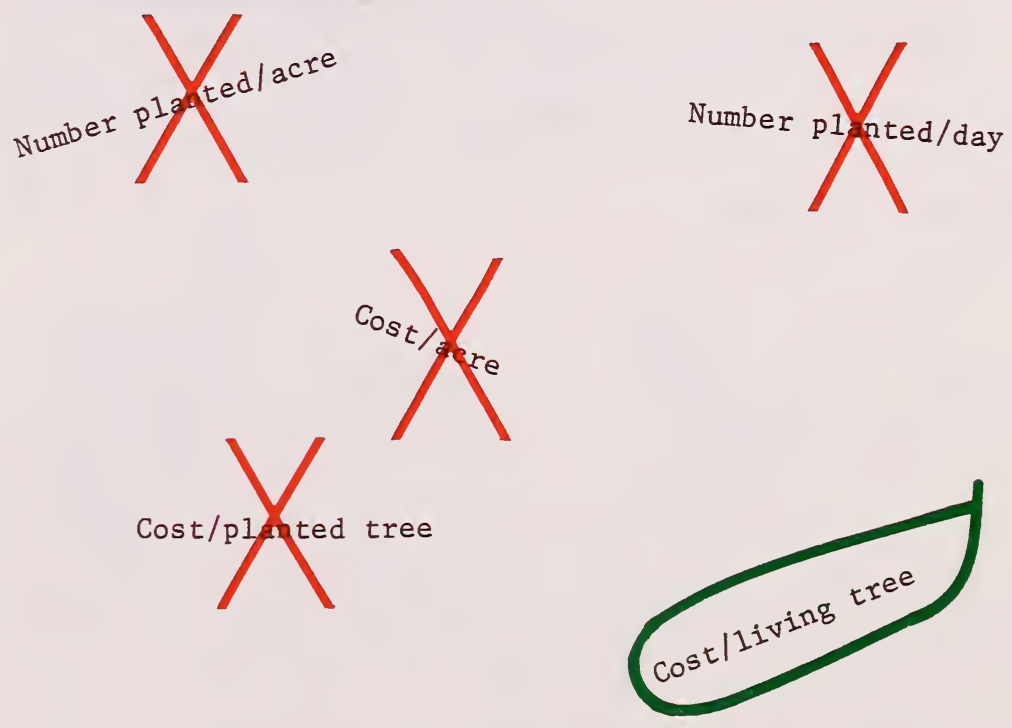


\section{COMMON CAUSES OF INJURY AND MORTALITY}

Rodent

Frost

Solarization - Most easily detected by yellow or yellowishgreen foliage; symptoms appear first in older foliage, but chlorosis is often evident in current growth by the end of the growing season.

Snow Mold - Brown or brownish-black mycelia of the fungi form dense mats over individual branches or entire seedlings; infected portion of seedling usually is dead.

Drought - Needles are a faded light green or blue green, are dry and brittle, and are usually retained on branches for some time. Incompletely developed, current-year shoots may wilt under severe dehydration. Dead needles that remain attached usually turn a dark reddish-brown within 7-10 days if soil moisture becomes available. Sometimes seedling death can be traced to desiccation resulting from planting error--loosely packed soil or doubled roots.

Browsing - The severed tissue of the stem on remaining branches is generally frayed or splintered.

Trampling - The stem or branches are broken, but usually are not separated. Animal tracks are also evident. 


